\title{
Simultaneous Determination and Occurrences of Pharmaceuticals by Solid-Phase Extraction and Liquid Chromatography-Tandem Mass Spectrometry (LC-MS/MS) in Environmental Aqueous Samples
}

\author{
So Hyun Koo, ${ }^{\dagger, \downarrow}$ Cheon Ho Jo, ${ }^{\dagger, \S}$ Sun Kyoung Shin, ${ }^{\dagger}$ and Seung-Woon Myung ${ }^{\dagger, *}$ \\ ${ }^{\dagger}$ Department of Chemistry, Kyonggi University, Suwon 443-760, Korea. ${ }^{*}$ E-mail: swmyung@kgu.ac.kr \\ Division of Chemicals Behavior Research, National Institute of Environmental Research, Incheon 404-708, Korea \\ ${ }^{\S}$ Division of Food Contaminants, Korea Food and Drug Administration, Eunpyeong-gu, Seoul 122-704l, Korea \\ Received December 11, 2009, Accepted February 26, 2010
}

\begin{abstract}
Pharmaceuticals and personal care products (PPCPs) are emerging contaminants in the aquatic environment. Many pharmaceuticals are not completely removed during wastewater treatment, leading to their presence in wastewater treatment effluents, rivers, lakes, and ground water. Here, we developed analytical methods for monitoring ten pharmaceuticals from surface water by LC/ESI-MS/MS. For sample clean-up and extraction, MCX (mixed cation exchange) and HLB (hydrophilic-lipophilic balance) solid-phase extraction (SPE) cartridges were used. The limits of detection (LOD) in distilled water and the blank surface water were in the range of $0.006-0.65$ and $1.66-45.05 \mathrm{pg} / \mathrm{mL}$, respectively. The limits of quantitation (LOQ) for the distilled water and the blank surface water were in the range of $0.02-2.17$ and $5.52-150.15 \mathrm{pg} / \mathrm{mL}$, respectively. The absolute recoveries for fortified water samples were between $62.1 \%$ and $125.4 \%$. Intra-day precision and accuracy for the blank surface water were $2.9 \%-24.1 \%$ (R.S.D.) and $-16.3 \%-16.3 \%$ (bias), respectively. In surface wastewater near rivers, chlortetracycline and acetylsalicylic acid were detected frequently in the range of $0.017-5.404$ and $0.029-0.269 \mathrm{ng} / \mathrm{mL}$, respectively. Surface water near rivers had higher levels than surface water of domestic treatment plants.
\end{abstract}

Key Words: Pharmaceuticals and personal care products, LC/MS/MS, Surface water

\section{Introduction}

The fate and effects of pharmaceuticals and personal care products (PPCPs) and natural estrogens entering the environment has gained increasing attention. PPCPs include non-prescription and prescription pharmaceuticals for human and veterinary use, and the active and inert ingredients in personal care products. ${ }^{1}$ PPCPs and EDCs (Endocrine disrupting chemicals) and their metabolites are continuously introduced into aquatic environments via sewage treatment plant effluent and/or agricultural runoff. ${ }^{2}$ Animal waste in pasturage or confined animal-feeding operations is another potential source of pharmaceuticals. Direct discharge to the ground from livestock excretion can contaminate surface water and can infiltrate ground water. ${ }^{3}$ Approximately 3000 different active substances are used in human and veterinary medicine, ${ }^{4}$ so their detection in environmental waters is of significant interest.

Thus, there has been growing interest in measuring emerging contaminants that are not currently covered by existing regulations on water quality, but that may be candidates for future regulation, depending on their toxicity and potential effects in the environment and on human health. ${ }^{5}$ PPCPs can originate from human usage and excretions and veterinary applications of a variety of products such as over-the-counter and prescription medications and fungicides and disinfectants used for industrial, domestic, agricultural, and livestock practices. ${ }^{1}$ The presence of pharmaceuticals in aquatic environments typically results from human excretion of metabolized or parent drug passing into sewage or septic systems and subsequent discharge of wastewater and percolation of septic-system leachate into surface water or ground water. ${ }^{6}$

The concentrations of pharmaceuticals found in surface water downstream from sewage treatment plant effluents are generally in the $\mathrm{ng} / \mathrm{L}$ range and do not necessarily represent a serious threat to drinking water quality. Unfortunately, the consequences of continuous exposure to low concentrations of pharmaceuticals in the ecosystem are still not fully known. A discussion of various aspects of ecotoxicology of pharmaceuticals in the environment can be found in recent reviews. ${ }^{7,8,9}$

Environmental risk assessment must be based on reliable data about the actual concentrations of pharmaceuticals in aquatic systems. Therefore, efficient analytical methods are of major importance. ${ }^{10}$

The quantitative analysis of antibiotics in the aqueous environment is difficult because of the fact that antibiotics exist in low concentration levels and the matrices are complicated and what's more, physico-chemical properties of antibiotics are diverse. Consequently, a highly sensitive and selective analytical method is crucially needed to monitor antibiotics in the aqueous environment.

The simultaneous determination of different analytes requires chromatographic techniques. ${ }^{5}$ Because of the recent awareness of the potentially dangerous consequences of the presence of pharmaceuticals in the environment, the analytical methodology for their determination in complex environmental matrices is still evolving, and the number of methods described in the literature has grown considerably. ${ }^{11}$

The development of analytical procedures for pharmaceutical residue analysis is facilitated by considerable experience in pesticide residue analysis. Common procedures include a pre- 
Table 1. Classification of pharmaceuticals

\begin{tabular}{clcc}
\hline Group & Pharmaceuticals & M.W. & pKa \\
\hline \multirow{6}{*}{ Group-A } & Acetaminophen & 151.2 & 9.5 \\
& Lincomycin & 406.5 & 7.79 \\
& Sulfamethazine & 278.3 & 7.4 \\
& Sulfamethoxazole & 253.3 & 5.8 \\
& Sulfathiazole & 255.3 & 7.2 \\
& Ttrimethoprim & 290.3 & 6.6 \\
\hline \multirow{6}{*}{ Group-B } & Chlortetracycline & 478.9 & $3.33 / 7.55 / 9.33$ \\
& Oxytetracycline & 460.4 & $3.22 / 7.46 / 8.94$ \\
& Ciprofloxacin & 331.3 & $6.09 / 8.74$ \\
& Enrofloxacin & 359.4 & $6.0 / 6.9$ \\
\hline
\end{tabular}

concentration and clean-up step by solid-phase extraction or related techniques, followed by chromatography in combination with mass spectrometry (MS) as a detector. For complex matrices, established sample preparation protocols may fail to allow sufficient sample clean-up to avoid ionization suppression in the atmospheric pressure ionization source of the MS detector. ${ }^{10}$

High-Performance liquid chromatography coupled to mass spectrometry (LC-MS), and particularly tandem mass spectrometry (LC-MS/MS), are the primary techniques used to determine ultra-trace concentrations of pharmaceuticals in wastewater, surface water, and ground water. ${ }^{5,11,12,13,14,15}$

Here, we have developed a sensitive and reliable analytical method for the simultaneous determination of ten pharmaceuticals in aquatic samples using a combined solid-phase extraction (SPE) isolation and clean-up, and LC/MS/MS with electrospray ionization (ESI) and multiple reaction monitoring (MRM). The limits of detection (LOD), limits of quantitation (LOQ), accuracy, and precision of the assay are described. The method was applied to target pharmaceuticals from surface water in South Korea. We selected the top ten pharmaceuticals prescribed in South Korea from 2000 to $2006,{ }^{16}$ both human and veterinary antibiotics (three sulfonamides (sulfamethazine, sulfamethoxazole, sulfathiazole), two tetracyclines (chlortetracycline, oxytetracycline), lincomycin, trimethoprim and two fluoroquinolones (enrofloxacin, ciprofloxacin)), as well as the analgesic/ anti-inflammatory drugs, acetaminophen.

For chromatographic separation and mass spectrometric analysis, ten pharmaceuticals were classified into two groups (Table 1). We also describe the impact of matrix effects when measuring these compounds at environmentally relevant concentrations.

\section{Experimental}

Chemicals and standards. Sulfamethazine, sulfamethoxazole, sulfathiazole, lincomycin, acetaminophen, chlortetracycline, and oxytetracycline were purchased from Sigma-Aldrich Co. (St Louis, MO, USA) and trimethoprim, enrofloxacin and ciprofloxacin from Fluka Co. (Seelze, Germany), all pharmaceutical standards were of analytical grade and high purity $(>90 \%)$. The reference compounds, used as surrogate standards, sulfamethazine- $6-{ }^{13} \mathrm{C}$, ciprofloxacin- $3{ }^{13} \mathrm{C}$ and ibuprofen- $-6{ }^{13} \mathrm{C}$, and in- ternal standard (terbutylazine) were purchased from Cambridge Isotope Laboratories Co. (Andover, MA, USA) and Fluka Co. (Seelze, Germany), respectively. Methanol, acetonitrile, and acetone were of HPLC grade (J.T. Baker Co, NJ, USA). All reagents were obtained from commercial sources and typically were at purities of $90 \%$ or greater : $\mathrm{Na}_{2}$-EDTA and $\mathrm{H}_{2} \mathrm{SO}_{4}$ (Junsei Co., Tokyo, Japan), HCl (Waco Co., Osaka, Japan), ammonium formate (Sigma-Aldrich Co., St Louis, MO, USA), ammonium acetate (Merck Co., Darmstadt, Germany), formic acid (Fluka Co., Seelze, Germany), and ammonium hydroxide (Samchun Co., Gyeonggi-do, Korea).

A stock solution of $1000 \mu \mathrm{g} / \mathrm{mL}$ was prepared in methanol and stored at $-20{ }^{\circ} \mathrm{C}$. Working standard solutions, at different concentrations, were prepared by appropriate dilution of the stock solution with methanol and stored in a refrigerator at $4{ }^{\circ} \mathrm{C}$. Surrogate mixtures were at a concentration of $100 \mu \mathrm{g} / \mathrm{mL}$ and stored at $-20{ }^{\circ} \mathrm{C}$.

Sampling and sample preparation. Samples were collected from surface water of four major rivers (the Han River, the Nakdong River, the Geum River and the Youngsan River) that receive the effluent of the waste water treatment plants. Amber glass bottles with Teflon-lined caps rinsed with ultra-pure water were used for sample collection. To characterize the nature of aquatic samples, conductivity, $\mathrm{pH}$, and temperature were measured during the sampling period. Samples were stored at $4{ }^{\circ} \mathrm{C}$ until sample extraction (within two weeks).

Before sample extraction, samples were centrifuged at $11,300 * \mathrm{~g}$ for $20 \mathrm{~min}$ and subsequently filtered through a $1.2 \mu \mathrm{m}$ glass fiber filter (Whatman, Clifton, NJ, USA) and a $0.45 \mu \mathrm{m}$ membrane filter (PALL Life Sciences, Mexico) to remove particulate matter prior to solid-phase extraction.

The sample extraction procedure was modified from reference (Karthikeyan and Meyer, 2006) ${ }^{15}$ for the simultaneous analysis. Samples $(500 \mathrm{~mL})$ were added to $5 \mathrm{~mL}$ of $0.1 \mu \mathrm{g} / \mathrm{mL}$ $\mathrm{Na}_{2}$-EDTA and $25 \mu \mathrm{L}$ of $10 \mu \mathrm{g} / \mathrm{mL}$ surrogate standards (sulfamethazine- $6-{ }^{13} \mathrm{C}$, ciprofloxacin- $-3-{ }^{13} \mathrm{C}$ and ibuprofen- $-6-{ }^{13} \mathrm{C}$ ) and adjusted to $\mathrm{pH} 3$ with $3.5 \mathrm{M}$ sulfuric acid. Oasis HLB, 200 mg, 6 cc (Waters, Milford, MA, USA), a copolymer made from a balanced ratio of hydrophilic N-vinylpyrrolidone and lipophilic divinylbenzene and Oasis MCX, $150 \mathrm{mg}, 6 \mathrm{cc}$ (Waters, Milford, MA, USA), were preconditioned sequentially with 2 $\mathrm{mL}$ of distilled water, $2 \mathrm{~mL}$ of methanol, $2 \mathrm{~mL}$ of $5 \% \mathrm{NH}_{4}$-hydroxide-methanol solution, $2 \mathrm{~mL}$ of distilled water, and $2 \mathrm{~mL}$ of distilled water ( $\mathrm{pH}$ 3.0). The HLB and MCX cartridges were connected in tandem. Samples were loaded through the combined SPE cartridge (HLB-MCX) at $10 \mathrm{~mL} / \mathrm{min}$. After sample loading, combined cartridges were separated. The HLB cartridge was then washed with $1 \mathrm{~mL}$ of distilled water and eluted with $8 \mathrm{~mL}$ of methanol, and the MCX cartridge was washed with 1 $\mathrm{mL}$ of distilled water. The two cartridges were re-combined and loaded with $2 \mathrm{~mL}$ of methanol, followed by elution with $6 \mathrm{~mL}$ of methanol. After removing the HLB cartridge from the MCX cartridge, MCX was eluted separately with $4 \mathrm{~mL}$ of $5 \% \mathrm{NH}_{4}-$ hydroxide-methanol solution. After eluent collection, $25 \mu \mathrm{L}$ of $10 \mu \mathrm{g} / \mathrm{mL}$ terbutylazine (for Group-A and -B) as internal standard was added. The combined aliquots were evaporated to dryness with a Turbo Vap (Zymark, Hopkinton, MA, USA) evaporative concentrator, using nitrogen at $40^{\circ} \mathrm{C}$. Samples were re- 
Table 2. HPLC chromatographic conditions and mass spectrometric parameters

\begin{tabular}{|c|c|c|}
\hline Parameters & Group-A & Group-B \\
\hline Column & $\begin{array}{l}\text { Eclipse Plus C18 column, } 2.1 \mathrm{~mm} \text { i.d., } 100 \mathrm{~mm} \text { length, } \\
3.5 \mu \mathrm{m} \text { particle size }\end{array}$ & $\begin{array}{l}\text { Luna C8 column, } 3 \mathrm{~mm} \text { i.d., } 150 \mathrm{~mm} \text { length, } 3 \mu \mathrm{m} \text { particle } \\
\text { size }\end{array}$ \\
\hline Mobile phase & $\begin{array}{l}\text { A: } 20 \mathrm{mM} \text { ammonium acetate }(\mathrm{pH} 6.5) \\
\text { B: Acetonitrile }\end{array}$ & $\begin{array}{l}\text { A: } 20 \mathrm{mM} \text { ammonium formate }(0.3 \% \text { formic acid }) \\
\text { B: Acetonitrile }\end{array}$ \\
\hline Gradient & $\begin{array}{lccccccc}\text { Time }(\min ) & 0 & 3 & 10 & 12 & 15 & 15.1 & 25 \\
\text { Solvent B(\%) } & 10 & 10 & 50 & 85 & 85 & 10 & 10\end{array}$ & $\begin{array}{lcccccc}\text { Time }(\min ) & 0 & 3 & 10 & 11 & 11.1 & 20 \\
\text { Solvent } \mathrm{B}(\%) & 20 & 20 & 80 & 80 & 20 & 20\end{array}$ \\
\hline Column flow rate & $0.3 \mathrm{~mL} / \mathrm{min}$ & $0.3 \mathrm{~mL} / \mathrm{min}$ \\
\hline Injection volume & $10 \mu \mathrm{L}$ & $10 \mu \mathrm{L}$ \\
\hline Column temp. & $25^{\circ} \mathrm{C}$ & $25^{\circ} \mathrm{C}$ \\
\hline Ionization mode & Positive ion electrospray & Positive ion electrospray \\
\hline Capillary voltage & $3.50 \mathrm{kV}$ & $3.50 \mathrm{kV}$ \\
\hline Gas temperature & $350{ }^{\circ} \mathrm{C}$ & $350^{\circ} \mathrm{C}$ \\
\hline Gas flow & $8 \mathrm{~L} / \min \left(\mathrm{N}_{2}\right)$ & $8 \mathrm{~L} / \min \left(\mathrm{N}_{2}\right)$ \\
\hline Nebulizer & $35 \mathrm{psi}$ & 35 psi \\
\hline
\end{tabular}

constituted with $500 \mu \mathrm{L}$ of ammonium acetate (pH 9.0). The reconstituted sample was filtered through a $0.45 \mu \mathrm{m}$ syringe filter before LC/MS/MS analysis.

Chromatography and mass spectrometry. LC-MS/MS mea surements were performed on an Agilent Technologies (Palo Alto, USA) model 1200 series HPLC equipped with a binary pump system and a coupled Agilent 6410 triple quadrupole mass spectrometer with an electrospray ionization (ESI) interface. After obtaining full scan spectra in scan mode, product ions were obtained from precursor ions in product ion mode, and then characteristic ions were selected for multiple reaction monitoring (MRM).

The chromatographic separation for Group-A was performed on a Eclipse Plus $\mathrm{C}_{18}$ column $(100 \times 2.1 \mathrm{~mm}$ I.D. $)$ with a particle size of $3.5 \mu \mathrm{m}$ (Agilent Technologies, Palo Alto, USA) and for Group-B on a Luna $\mathrm{C}_{8}$ column $(150 \times 3.0 \mathrm{~mm}$ I.D. $)$ with a particle size of $3.0 \mu \mathrm{m}$ (Phenomonex, Torrance, CA, USA). Optimal separation was achieved with a binary mobile phase, and the mobile phase composition and gradients for two methods are shown in Table 2.

The optimal working parameters for the mass spectrometer were: capillary voltage, $3.5 \mathrm{kV}$; nebulizer temperature, $350{ }^{\circ} \mathrm{C}$; drying gas flow, $8 \mathrm{~L} / \mathrm{min}\left(\mathrm{N}_{2}\right)$. The electrospray ionization modes for Group-A and -B were positive ion.

\section{Results and Discussion}

Chromatographic separation and mass spectrometry. Instrumental analysis of pharmaceuticals was performed according to the physico-chemical properties. To improve mass peak separation quality and maximize method sensitivity, we modified the mobile phase composition with different organic modifiers. The optimal gradients of HPLC are shown Table 2. In each group, pharmaceuticals were separated effectively without overlap, and total ion chromatogram (TIC) and extracted ion chromatograms (EIC) are shown in Fig. 1-2.

Because Group-A and -B pharmaceuticals are basic compounds, the base peak in full scan spectrum was typically [M+ $\mathrm{H}]^{+}$, and the precursor ion was $[\mathrm{M}+\mathrm{H}]^{+}$. For analysis of Group-A

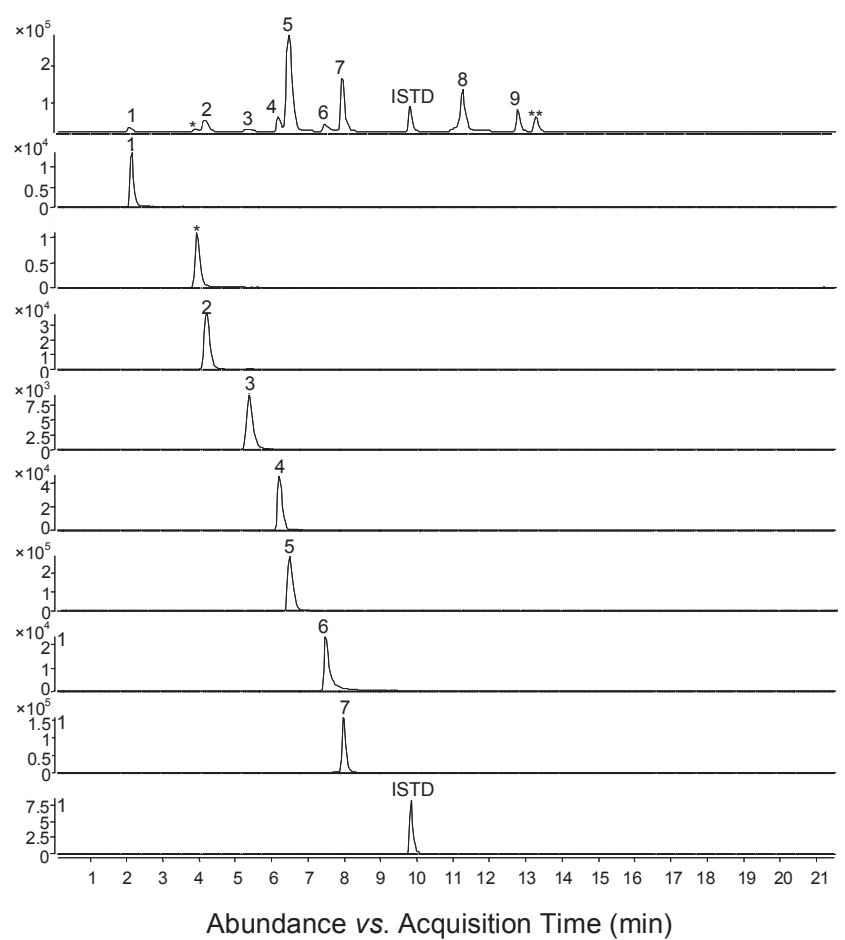

Figure 1. Total ion chromatogram and extracted ion chromatograms of Group-A pharmaceuticals: 1 = acetaminophen, 2 = sulfathiazole, $3=$ sulfamethoxazole, $4=$ carbadox, $5=$ sulfamethazine, $6=$ trimethoprim, $7=$ lincomycin and ISTD $=$ terbutylazine.

and -B, chromatographic retention time, precursor ion, product ions, and collision energies are shown in Table 3-4. The "quantitation ion" with the higher intensity was used as a quantifier, and "confirmation ion" with lower intensity was used for qualifier.

Calibration curve. The internal standard for Group-A and -B, terbutylazine, eluted within the appropriate chromatographic time frame as the analytes, responded well in positive ion ESI mode, and did not exhibit noticeable matrix effects. Terbutylazine was not detected in any of the aquatic samples selected as the reference matrices for quantification. 


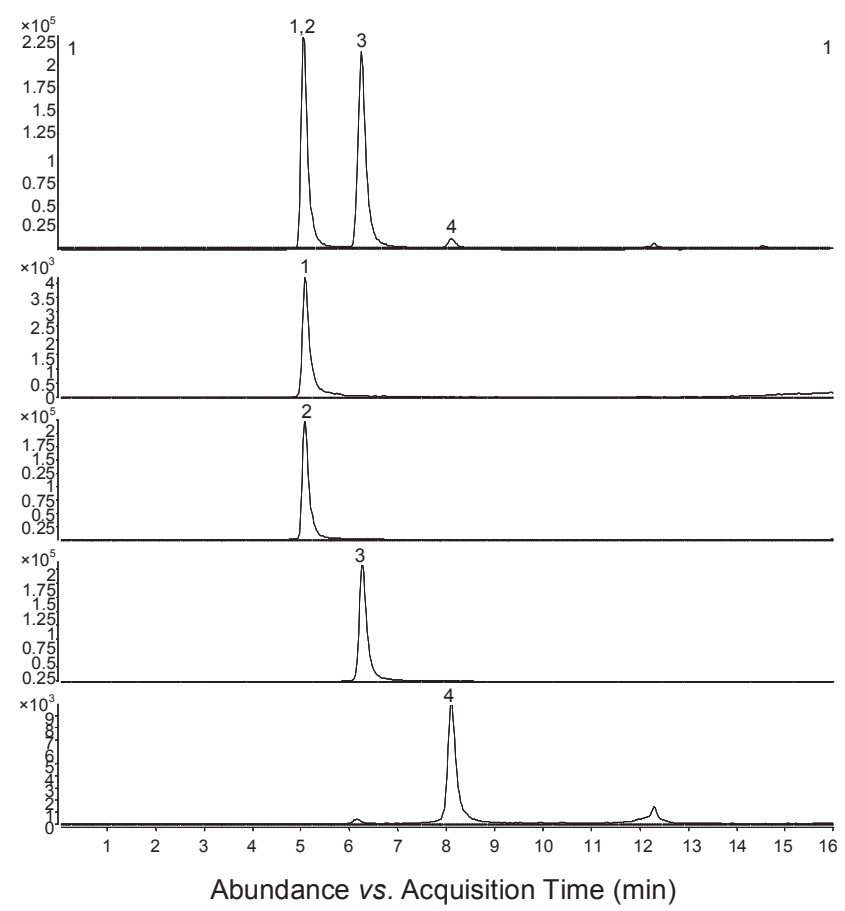

Figure 2. Total ion chromatogram and extracted ion chromatograms of Group-B pharmaceuticals: 1 = oxytetracycline, $2=$ ciprofloxacin, $3=$ enrofloxacin and $4=$ chlortetracycline.

The calibration curves were made from the peak area ratio of the pharmaceuticals to the internal standard (terbutylazine). The concentrations of the spiked analytes in the blank surface water were between $0.01 \sim 1 \mathrm{ng} / \mathrm{mL}$. Calibration curves were linear with correlation coefficients $\left(\mathrm{R}^{2}>0.99\right)$ (except oxytetracycline) in the spiked concentration level (Table 5).

Limit of detection (LOD) and limit of quantitation (LOQ). The limit of detection (LODs) was defined as the lowest concentration at which the signal to noise ratio $(\mathrm{S} / \mathrm{N})$ were $\geq 3$, and the limit of quantitation (LOQs) was defined as a concentration where $\mathrm{S} / \mathrm{N}$ is $\geq 10$, with accuracy and precision both within $20 \%$. The LOD and LOQ for pharmaceuticals were determined by spiking with each concentrations of pharmaceuticals in distilled water and blank surface water. Blank surface water samples with no target antibiotics detected were used as blank surface water.

The limits of detection for the distilled water and the blank surface water were in the range of $0.006 \sim 0.65$ and $1.66 \sim 45.05$ $\mathrm{pg} / \mathrm{mL}$, respectively. The limits of quantitation for the distilled water and the blank surface water were in the range of $0.02 \sim$ 2.17 and $5.52 \sim 150.15 \mathrm{pg} / \mathrm{mL}$, respectively (Table 6). These result from the matrix effect could negatively interact with the SPE cartridges (saturation of the SPE active sites with natural organic matter) leading to lower absolute recoveries and ionization suppression in MS.

In this study, the limit of quantitation for the established analytical method was found to be lower than $10 \sim 50 \mathrm{pg} / \mathrm{mL}$ reported in previous studies, ${ }^{15}$ proving to be a sensitive method.

Recovery, precision, and accuracy. Intra-day precision and accuracy were evaluated by three replicates of spiked distilled water and blanked surface water at low $(0.1 \mathrm{ng} / \mathrm{mL})$ and high $(1 \mathrm{ng} / \mathrm{mL})$ concentrations on the same day. The precisions and accuracies for the distilled water were $3.2 \sim 14.6 \%$ (R.S.D.) and $-12.4 \sim 20.6 \%$ (bias), respectively. The precisions and accuracies for the blank surface water were $2.9 \sim 24.1 \%$ (R.S.D.)

Table 3. Retention time, precursor ion, product ions, and collision energies for Group-A analysis

\begin{tabular}{lcccccc}
\hline \multicolumn{1}{c}{ Pharmaceuticals } & $\begin{array}{c}\text { R.T. } \\
(\mathrm{min})\end{array}$ & $\begin{array}{c}\text { Precursor ion } \\
(\mathrm{m} / \mathrm{z})\end{array}$ & Confirmation ion $(\mathrm{m} / \mathrm{z})$ & $\begin{array}{c}\text { Quantitation ion } \\
(\mathrm{m} / \mathrm{z})\end{array}$ & $\begin{array}{c}\text { Collision } \\
\text { Energy }(\mathrm{eV})\end{array}$ \\
\hline Acetaminophen & 2.16 & 152 & 152 & 93 & 110 & 15 \\
Sulfathiazole & 4.22 & 256 & 108 & 92 & 156 & 15 \\
Lincomycin & 7.95 & 407 & 407 & 359 & 126 & 20 \\
Sulfamethoxazole & 5.36 & 254 & 108 & 99 & 156 & 15 \\
Trimethoprim & 7.47 & 291 & 123 & 261 & 230 & 25 \\
Sulfamethazine & 6.49 & 279 & 279 & 124 & 186 & 15 \\
Sulfamethazine-6- ${ }^{13} \mathrm{C}$ (surrogate standard) & 6.49 & 285 & 124 & 285 & 186 & 20 \\
Terbutylazine (ISTD) & 9.84 & 212 & 86 & 114 & 156 & 15 \\
\hline
\end{tabular}

Table 4. Retention time, precursor ion, product ions, and collision energies for Group-B analysis

\begin{tabular}{lcccccc}
\hline \multicolumn{1}{c}{ Pharmaceuticals } & $\begin{array}{c}\text { R.T. } \\
(\mathrm{min})\end{array}$ & $\begin{array}{c}\text { Precursor ion } \\
(\mathrm{m} / \mathrm{z})\end{array}$ & Confirmation ion $(\mathrm{m} / \mathrm{z})$ & $\begin{array}{c}\text { Quantitation ion } \\
(\mathrm{m} / \mathrm{z})\end{array}$ & $\begin{array}{c}\text { Collision } \\
\text { Energy }(\mathrm{eV})\end{array}$ \\
\hline Chlortetracycline & 8.09 & 479 & 444 & 154 & 462 & 20 \\
Oxytetracycline & 5.09 & 461 & 443 & 461 & 426 & 20 \\
Ciprofloxacin & 5.07 & 332 & 288 & 332 & 314 & 15 \\
Enrofloxacin & 6.26 & 360 & 316 & 360 & 342 & 15 \\
Ciprofloxacin-3- ${ }^{13} \mathrm{C}$ (surrogate standard) & 5.07 & 335 & 290 & 335 & 317 & 15 \\
Terbutylazine (ISTD) & 10.8 & 212 & 86 & 114 & 156 & 15 \\
\hline
\end{tabular}


Table 5. Correlation coefficients $\left(\mathrm{R}^{2}\right)$ and linear equation for the spiked surface water (concentration range : $0.01-1 \mathrm{ng} / \mathrm{mL}$ )

\begin{tabular}{clcc}
\hline Group & \multicolumn{1}{c}{ Pharmaceuticals } & Correlation Coefficient $\left(\mathrm{R}^{2}\right)$ & Linear equation \\
\hline \multirow{6}{*}{ Group-A } & Acetaminophen & 0.9994 & $\mathrm{y}=1.5717 \mathrm{x}-0.0132$ \\
& Trimethoprim & 0.9991 & $\mathrm{y}=0.3847 \mathrm{x}-0.0064$ \\
& Lincomycin & 0.9993 & $\mathrm{y}=1.8639 \mathrm{x}-0.0202$ \\
& Sulfamethazine & 0.9988 & $\mathrm{y}=0.8051 \mathrm{x}-0.0126$ \\
& Sulfamethoxazole & 0.9991 & $\mathrm{y}=0.3714 \mathrm{x}-0.0029$ \\
& Sulfathiazole & 0.9977 & $\mathrm{y}=1.2245 \mathrm{x}-0.0202$ \\
\hline \multirow{3}{*}{ Group-B } & Chlortetracycline & 0.9900 & $\mathrm{y}=0.9453 \mathrm{x}-0.0458$ \\
& Oxytetracycline & 0.9802 & $\mathrm{y}=0.2666 \mathrm{x}-0.0171$ \\
& Ciprofloxacin & 0.9948 & $\mathrm{y}=1.3144 \mathrm{x}-0.0845$ \\
& Enrofloxacin & 0.9964 & $\mathrm{y}=3.997 \mathrm{x}-0.2596$ \\
\hline
\end{tabular}

Table 6. Limit of detection (LODs) and limit of quantitation (LOQs) in distilled water and blank surface water $(\mathrm{pg} / \mathrm{mL})(\mathrm{n}=4)$

\begin{tabular}{|c|c|c|c|c|c|}
\hline \multirow{2}{*}{ Group } & \multirow{2}{*}{ Pharmaceuticals } & \multicolumn{2}{|c|}{ Distilled water } & \multicolumn{2}{|c|}{ Blank surface water } \\
\hline & & LOD & LOQ & LOD & LOQ \\
\hline \multirow{6}{*}{ Group-A } & Acetaminophen & 0.44 & 1.47 & 3.13 & 10.43 \\
\hline & Sulfathiazole & 0.05 & 0.17 & 1.66 & 5.52 \\
\hline & Lincomycin & 0.02 & 0.09 & 8.29 & 27.62 \\
\hline & Sulfamethoxazole & 0.65 & 2.17 & 7.31 & 24.35 \\
\hline & Trimethoprim & 0.18 & 0.60 & 9.48 & 31.59 \\
\hline & Sulfamethazine & 0.006 & 0.02 & 11.65 & 38.82 \\
\hline \multirow{4}{*}{ Group-B } & Chlortetracycline & 0.05 & 0.17 & 12.61 & 42.02 \\
\hline & Oxytetracycline & 0.12 & 0.40 & 45.05 & 150.15 \\
\hline & Enrofloxacin & 0.04 & 0.15 & 24.88 & 82.92 \\
\hline & Ciprofloxacin & 0.04 & 0.13 & 8.19 & 27.31 \\
\hline
\end{tabular}

Table 7. Absolute recoveries, precision, and accuracy for pharmaceuticals in distilled water and blank surface water

\begin{tabular}{|c|c|c|c|c|c|c|c|}
\hline \multirow{2}{*}{ Group } & \multirow{2}{*}{ Pharmaceuticals } & \multirow{2}{*}{ Conc. (ng/mL) } & \multicolumn{3}{|c|}{ Distilled water } & \multicolumn{2}{|c|}{ Blank surface water } \\
\hline & & & Recovery (\%) & RSD (\%) & $\operatorname{Bias}(\%)^{*}$ & RSD (\%) & $\operatorname{Bias}(\%)^{*}$ \\
\hline \multirow{12}{*}{ Group-A } & \multirow{2}{*}{ Acetaminophen } & 0.1 & 81.9 & 3.5 & 4.6 & 7.1 & 4.2 \\
\hline & & 1 & 86.9 & 8.1 & -0.2 & 7.0 & 1.0 \\
\hline & \multirow{2}{*}{ Sulfathiazole } & 0.1 & 86.6 & 9.2 & 1.5 & 10.3 & 3.4 \\
\hline & & 1 & 79.7 & 7.8 & 2.0 & 7.8 & -1.5 \\
\hline & \multirow{2}{*}{ Lincomycin } & 0.1 & 65.1 & 8.0 & 2.7 & 7.9 & 2.0 \\
\hline & & 1 & 62.1 & 6.2 & 1.9 & 3.0 & 0.7 \\
\hline & \multirow{2}{*}{ Sulfamethoxazole } & 0.1 & 94.1 & 5.3 & 8.2 & 4.1 & 1.6 \\
\hline & & 1 & 81.5 & 5.4 & -1.7 & 9.9 & -0.9 \\
\hline & \multirow{2}{*}{ Trimethoprim } & 0.1 & 95.8 & 8.4 & -4.6 & 10.7 & 0.6 \\
\hline & & 1 & 92.2 & 7.9 & 4.3 & 5.8 & -0.1 \\
\hline & \multirow{2}{*}{ Sulfamethazine } & 0.1 & 91.1 & 6.9 & -6.9 & 9.6 & -1.3 \\
\hline & & 1 & 83.9 & 7.3 & 4.7 & 16.2 & -1.0 \\
\hline \multirow{8}{*}{ Group-B } & \multirow{2}{*}{ Chlortetracycline } & 0.1 & 77.1 & 11.7 & 2.8 & 17.9 & 16.3 \\
\hline & & 1 & 75.5 & 11.2 & -1.3 & 24.1 & -16.3 \\
\hline & \multirow{2}{*}{ Oxytetracycline } & 0.1 & 125.4 & 14.2 & 20.6 & 4.0 & 11.1 \\
\hline & & 1 & 123.7 & 14.6 & -6.1 & 2.9 & 9.5 \\
\hline & \multirow{2}{*}{ Enrofloxacin } & 0.1 & 72.8 & 5.5 & -0.8 & 10.9 & 12.5 \\
\hline & & 1 & 82.3 & 7.6 & -4.3 & 5.3 & 3.7 \\
\hline & \multirow{2}{*}{ Ciprofloxacin } & 0.1 & 84.4 & 3.2 & -12.4 & 3.2 & 7.0 \\
\hline & & 1 & 96.9 & 9.0 & 3.7 & 4.3 & 3.5 \\
\hline
\end{tabular}

$* \operatorname{Bias}(\%)=\frac{\text { Calculated Value }- \text { Measured Value }}{\text { Calculated Value }} \times 100$ 
Table 8. Occurrence and fate of the pharmaceuticals from the surface water of the river that receives the effluent of the domestic WWTP(ng/mL)

\begin{tabular}{|c|c|c|c|c|}
\hline \multirow[b]{2}{*}{ Group } & \multirow[b]{2}{*}{ Pharmaceuticals } & \multicolumn{3}{|c|}{ Surface water } \\
\hline & & $\begin{array}{l}\text { Average Concentration of } \\
\text { detected values }\end{array}$ & Concentration Range & Number of Detection \\
\hline \multirow{6}{*}{ Group-A } & Acetaminophen & 0.006 & N.D. -0.137 & $1 / 24$ \\
\hline & Sulfathiazole & 0.082 & N.D. - 1.882 & $4 / 24$ \\
\hline & Lincomycin & 0.020 & N.D. -0.246 & $8 / 24$ \\
\hline & Sulfamethoxazole & 0.018 & N.D. -0.168 & $5 / 24$ \\
\hline & Trimethoprim & 0.001 & N.D. -0.012 & $2 / 24$ \\
\hline & Sulfamethazine & 0.012 & N.D. - 0.296 & $1 / 24$ \\
\hline \multirow{4}{*}{ Group-B } & Chlortetracycline & 0.308 & N.D. - 5.404 & $9 / 24$ \\
\hline & Oxytetracycline & N.D & N.D & $0 / 24$ \\
\hline & Enrofloxacin & 0.006 & N.D. -0.076 & $3 / 24$ \\
\hline & Ciprofloxacin & 0.0001 & N.D. - 0.001 & $1 / 24$ \\
\hline
\end{tabular}

Table 9. Occurrence and fate of pharmaceuticals from the surface water of the river that receives the effluent of the livestock WWTP (ng/mL)

\begin{tabular}{|c|c|c|c|c|}
\hline \multirow{2}{*}{ Group } & \multirow{2}{*}{ Pharmaceuticals } & \multicolumn{3}{|c|}{ Surface water } \\
\hline & & Average Concentration & Concentration Range & Number of Detection \\
\hline \multirow{6}{*}{ Group-A } & Acetaminophen & 0.008 & N.D. -0.126 & $1 / 16$ \\
\hline & Sulfathiazole & 0.115 & N.D. - 1.377 & $7 / 16$ \\
\hline & Lincomycin & 0.064 & N.D. -0.343 & $7 / 16$ \\
\hline & Sulfamethoxazole & 0.038 & N.D. -0.435 & $2 / 16$ \\
\hline & Trimethoprim & 0.002 & N.D. -0.021 & $2 / 16$ \\
\hline & Sulfamethazine & 0.025 & N.D. -0.304 & $2 / 16$ \\
\hline \multirow{4}{*}{ Group-B } & Chlortetracycline & 0.168 & N.D. -2.237 & $9 / 16$ \\
\hline & Oxytetracycline & N.D & N.D & $0 / 16$ \\
\hline & Enrofloxacin & 0.006 & N.D. -0.087 & $2 / 16$ \\
\hline & Ciprofloxacin & 0.001 & N.D. -0.011 & $2 / 16$ \\
\hline
\end{tabular}

and $-16.3 \sim 16.3 \%$ (bias), respectively. The precisions and accuracies were poorer in surface water than in distilled water. The tetracyclines (chlortetracycline and oxytetracycline) showed poor precisions and accuracies. The bias (\%) was defined as Calculated Value - Measured Value Calculated Value

within acceptable values of $-30 \%$ to $+20 \%$ at each concentration level. ${ }^{17}$ Recoveries, precision, and accuracy are shown in Table 7.

Occurrence and fate of pharmaceuticals. The modified and validated method was applied to the measurement of pharmaceuticals from the surface water of the river that receives the effluent of the domestic and livestock WWTP. Samples were collected twice at the same site on different dates: The first sampling date was the end of June, 2007, during the dry season (shortage of water), and the second sampling date was in the middle of August, 2007.

Reported averages are derived using all quantifiable values. In surface water of the river that receives the effluent of the domestic WWTP, lincomycin and chlortetracycline were detected frequently, at $0.002 \sim 0.246$ and $0.017 \sim 5.404 \mathrm{ng} / \mathrm{mL}$, respec- tively. Oxytetracycline was not found (Table 8).

For the surface water of the river that receives the effluent of the livestock WWTP, the most frequently detected pharmaceuticals were sulfathiazole, chlortetracycline, and lincomycin, which are only for veterinary or both human and veterinary prescription (Table 9). Overall, surface water contamination near livestock WWTPs was higher than near domestic WWTPs (from median values).

\section{Conclusions}

We have developed a effective and sensitive method for quantitation of ten pharmaceuticals using simultaneous solid-phase extraction and LC-MS/MS in aquatic samples. This method allows simultaneous extraction and clean-up of ten pharmaceuticals compounds with different physical-chemical properties, measuring below concentrations of $0.02 \sim 2.17 \mathrm{pg} / \mathrm{mL}$ for distilled water and $5.52 \sim 150.15 \mathrm{pg} / \mathrm{mL}$ for blank surface water. The method could be successfully applied to monitoring surface water in the major rivers in South Korea. 


\section{References}

1. Daughton, C. G.; Ternes, T. A. Environ. Health Perspect. 1999, 107, 907.

2. Kolpin, D.W. ; Furlong, E. T.; Meyer, M. T.; Thurman, E. M.; Zaugg, S. D.; Barber, L. B.; Buxton, H. T. Environ. Sci. Technol. 2002, 36, 1201.

3. Cahill, J. D.; Furlong, E. T.; Burkhardt, M. R.; Kolpin, D.; Anderson, L. G. J. Chromatogr. A 2004, 1041, 171.

4. Richardson, S. D. Anal. Chem. 2006, 78, 4021.

5. Hernandez, F.; Sancho, J. V.; Ibanez, M.; Guerrero, C. Trends Anal. Chem. 2007, 26, 466.

6. Ternes, T. A.; Hirsch, R.; Mueller, J.; Haberer, K.; Feresenius, J. Anal. Chem. 1998, 363, 329.

7. Cunningham, V. L.; Buzby, M.; Hutchinson, T.; Mastrocco, F.; Parke, N.; Roden, N. Env. Sci. Technol. 2006, 40, 3457.

8. Fent, K.; Weston, A. A.; Caminada, D. Aquatic. Toxicol. 2006, 76, 122.
9. Crane, M.; Watts, C.; Boucard, T. Sci. Tot. Environ. 2006, 367, 23.

10. Buchberger, W. W. Anal. Chim. Acta 2007, 593, 129.

11. Gomez, M. J.; Petrovic, M.; Fernandez-Alba, A. R.; Barcelo, D. J. Chromatogr. A 2006, 1114, 224

12. Abuin, S.; Codony, R.; Compano, R.; Granados, M.; Prat, M. D. J. Chromatogr. A 2006, 1114, 73.

13. Miao, X. S.; Bishay, F.; Chen, M.; Metcalfe, C. D. Environ. Sci. Technol. 2004, 38, 3533.

14. Renew, J. E.; Huang, C. H. J. Chromatogr. A 2004, 1042, 113.

15. Karthikeyan, K. G.; Meyer, M. T. Sci. Total Environ. 2006, 361, 196.

16. Development of Analytical Method and Study of Exposure of Pharmaceuticals and Personal Care Products in Enviroment; National Institute of Environmental Research, 2006.

17. Cherlet, M.; De Baere, S.; Croubels, S.; De Backer, P. Anal. Chim. Acta 2002, 473, 167.

18. Cha, J. M.; Yang, S.; Carlson, K. H. J. Chromatogr. A 2006, 1115, 46. 